\title{
Off-pump versus on-pump coronary artery bypass grafting: comparative effectiveness
}

This article was published in the following Dove Press journal:

Comparative Effectiveness Research

4 November 2015

Number of times this article has been viewed

\section{Shahzad G Raja}

Department of Cardiac Surgery, Harefield Hospital, London, UK
Correspondence: Shahzad G Raja Department of Cardiac Surgery, Harefield Hospital, Hill End Road, Harefield, Middlesex UB96JH, UK Tel +44 I8 958265 I I

$\mathrm{Fax}+441895828992$

Email drrajashahzad@hotmail.com
Background: Historically, coronary artery bypass grafting (CABG) with the use of cardiopulmonary bypass ( $\mathrm{CPB}$ ), referred to as on-pump $\mathrm{CABG}$, has been regarded as the "gold standard". However, in recent years, it has been increasingly recognized that the systemic inflammatory response associated with using CPB contributes substantially to postoperative organ dysfunction. Intuitively, performance of $\mathrm{CABG}$ without $\mathrm{CPB}$, referred to as off-pump $\mathrm{CABG}$, should translate into improved clinical outcomes. Interestingly, no single randomized trial has been able to prove the superiority of off-pump CABG over on-pump CABG for all hard outcomes, and off-pump CABG remains the subject of intense scrutiny as well as controversy. The purpose of the review is to summarize the current best available evidence, comparing the effectiveness of off- and on-pump CABG.

Methods: The English language scientific literature was reviewed primarily by searching MEDLINE from January 2010 to December 2014 using PubMed interface to identify metaanalyses and systematic reviews of randomized controlled trials as well as observational studies using propensity score matching, comparing the effectiveness of off- and on-pump CABG.

Results: Current best available evidence from meta-analyses and systematic reviews of randomized controlled trials as well as propensity score analyses suggests that off-pump CABG is associated with fewer distal anastomoses, increased repeat revascularization rates, and poor saphenous vein graft patency compared with on-pump CABG. No significant differences were observed for other hard outcomes including mortality, myocardial infarction, and stroke.

Conclusion: Off-pump CABG compared to on-pump CABG is associated with similar short-, mid-, and long-term mortality, comparable organ protection, and fewer distal anastomoses. The concerns about the safety and efficacy of off-pump CABG are not substantiated by the current best available evidence. However, the impact of learning curve on outcomes remains a valid issue.

Keywords: cardiopulmonary bypass, coronary artery bypass grafting, off-pump coronary artery bypass grafting, on-pump coronary artery bypass grafting, meta-analysis

\section{Introduction}

Coronary artery bypass grafting $(\mathrm{CABG})$ remains the preferred treatment in patients with complex coronary artery disease in the current era of tremendous upsurge in the use of percutaneous interventions for the treatment of symptomatic coronary artery disease. Traditionally, CABG has been performed with the aid of cardiopulmonary bypass (CPB), enabling the construction of coronary anastomoses on a still heart in a bloodless field. ${ }^{1}$ This on-pump CABG technique has remained the gold standard with which all other surgical revascularization methods have been compared. However, conventional on-pump CABG, despite its well-recognized safety and efficacy, is associated 
with a profound systemic inflammatory response secondary to the use of CPB. This systemic inflammatory response to $\mathrm{CPB}$ has the potential of causing myocardial ischemic injury, neurocognitive deficits, strokes, as well as pulmonary, renal, and hematologic complications. ${ }^{2}$

A rational way of counteracting the effects of this inflammatory response may be the avoidance of CPB itself. This idea provided the catalyst for rejuvenation of off-pump CABG - a technique that predates CPB but was rapidly replaced by on-pump CABG soon after the invention of the extracorporeal circulation. ${ }^{1}$ The initial enthusiasm that off-pump CABG will result in superior outcomes has been recently met with growing concern that it is associated with incomplete revascularization, suboptimal graft patency, and worse long-term survival compared with conventional onpump CABG. ${ }^{3}$ These concerns have fueled a lot of skepticism about the place of off-pump CABG as a recognized treatment option for coronary artery disease. The only means of countering this skepticism is by comparing the effectiveness of off- and on-pump CABG through the explicit and conscientious assessment of current best available evidence.

A logical and comprehensive approach to evaluating clinically relevant research incorporates many different types of evidence (including randomized controlled trials [RCTs], nonrandomized controlled trials, and experimental data) and analyzes the information's content for consistency, coherence, and clarity. ${ }^{4}$ It has long been recognized that not all research designs are equal in terms of the risk of error and bias in their results. When seeking answers to specific questions, some research methods provide better evidence than that provided by other methods. That is, the validity of the results of research varies as a consequence of the different methods used. For example, when evaluating the effectiveness of an intervention, the RCT is considered to provide the most reliable evidence. ${ }^{5}$ It is considered the most reliable evidence because the processes used during the conduct of an RCT minimize the risk of confounding factors influencing the results. As a result of this, the findings generated by RCTs are likely to be closer to the true effect than that generated by other research methods. ${ }^{5}$ However, the conduct of RCTs is costly and often inefficient due to the large number of participants needed to estimate the treatment effects with adequate precision. ${ }^{6}$ Furthermore, conducting RCTs may not be feasible or even ethical for all clinical questions of interest, and restrictive selection criteria can limit the external validity of their results. ${ }^{7}$

Observational studies are often a practical alternative to efficiently obtain estimates of the effectiveness of treatment in nonexperimental, routine-care settings. Nonetheless, the lack of randomization and other RCT design elements renders observational studies susceptible to biases, including confounding (and particularly confounding by factors that affect treatment choice and are also causally associated with the outcome), selection, and differential ascertainment bias. ${ }^{8}$ Proposed as a potential solution to the problem of confounding of the treatment-outcome association, a propensity score expresses the probability of having been treated with an intervention based on variables measured at or before the time of treatment. ${ }^{9,10}$ Analyses using propensity score methods attempt to emulate randomized comparisons, because they allow contrasts between patient groups that are on average similar on all observed confounders.

A rational approach to comparing the effectiveness of two treatment strategies will be to take into consideration evidence from RCTs as well as propensity score-matched observational studies. In recent years, with the increasing popularity of systematic reviews, these are starting to replace the RCT as the best source of evidence. ${ }^{5}$ This review article attempts to assess the comparative effectiveness of off- and on-pump CABG by evaluating the current best available evidence from most up-to-date systematic reviews and meta-analyses of RCTs as well as propensity score-matched observational studies.

\section{Methods}

\section{Search methodology}

The English language scientific literature was only reviewed primarily by searching MEDLINE from January 2010 to December 2014 using PubMed interface. ${ }^{11}$ Keywords used in the search included MeSH terms: meta-analysis, CPB, extracorporeal circulation, coronary artery bypass surgery, CABG, and off-pump coronary artery bypass. In addition, non-MeSH terms such as systematic review, CABG, on-pump coronary artery bypass surgery, OPCAB, off-pump coronary artery bypass surgery, and beating heart coronary artery surgery were also used. The "related articles" function was used to broaden the search, and all abstracts, studies, and citations scanned were reviewed. The reference lists of articles found through these searches were also reviewed for relevant articles. In addition, links on Web sites (e-library, CINAHL [Cumulative Index to Nursing and Allied Health Literature], DARE [Database of Abstracts of Reviews of Effectiveness], and EMBASE) containing published articles were searched for relevant information. The author of this article chose systematic reviews and meta-analysis of RCTs only relevant to the topic. The search was done in stages so as to achieve 
the search strategy with a high sensitivity (meaning that it has the highest likelihood of retrieving all relevant articles). Similar search terms were combined using the Boolean operator "OR" to find all abstracts that contained information about a particular search term. These individual terms were then combined using the Boolean operator "AND" to find articles that contained information on all the search terms. This is a well-recognized method for performing sensitive searches and has been described in detail in the British Medical Journal. ${ }^{12}$

\section{Inclusion criteria}

All meta-analyses or systematic reviews of blinded or unblinded RCTs as well as propensity score-matched observational studies comparing off-pump CABG on the beating heart with conventional on-pump CABG on $\mathrm{CPB}$ using cardioplegic arrest, recruiting adult human patients undergoing multivessel bypass grafting, and reporting impact of these two techniques on any clinical outcome published between January 2010 and December 2014 were included. Meta-analyses reporting on the outcomes of hybrid revascularization procedures, robotically assisted surgery, using circulatory assist devices, or comparing off-pump CABG with drug-eluting stents were excluded. The rationale for including meta-analyses or systematic reviews published from January 2010 onward was only to ensure that the meta-analyses included ROOBY, DOORS, CORONARY, and GOPCABE trials, the four large multiinstitutional trials that first reported the outcomes in 2009, 2012, and 2013. ${ }^{13-16}$

\section{Data extraction and validation of the studies}

The articles found by the search strategy (Figure 1) were then appraised. The appraisal of each article was performed in a structured format, using critical appraisal checklists. These are widely available in several formats and aid in assessing the article for methodological and analytical soundness and help uncover any significant methodological flaws. ${ }^{17}$ The following information was extracted from each study: first author, year of publication, included studies, number of patients operated on with each technique, and key outcomes (Table 1).

\section{Results \\ Evidence from meta-analysis of RCTs} In-hospital mortality

Sá et $\mathrm{al}^{18}$ published a meta-analysis of $47 \mathrm{RCT}$ including a total of 13,524 patients $(6,758$ for off-pump and 6,766 for on-pump CABG). The in-hospital or 30-day mortality

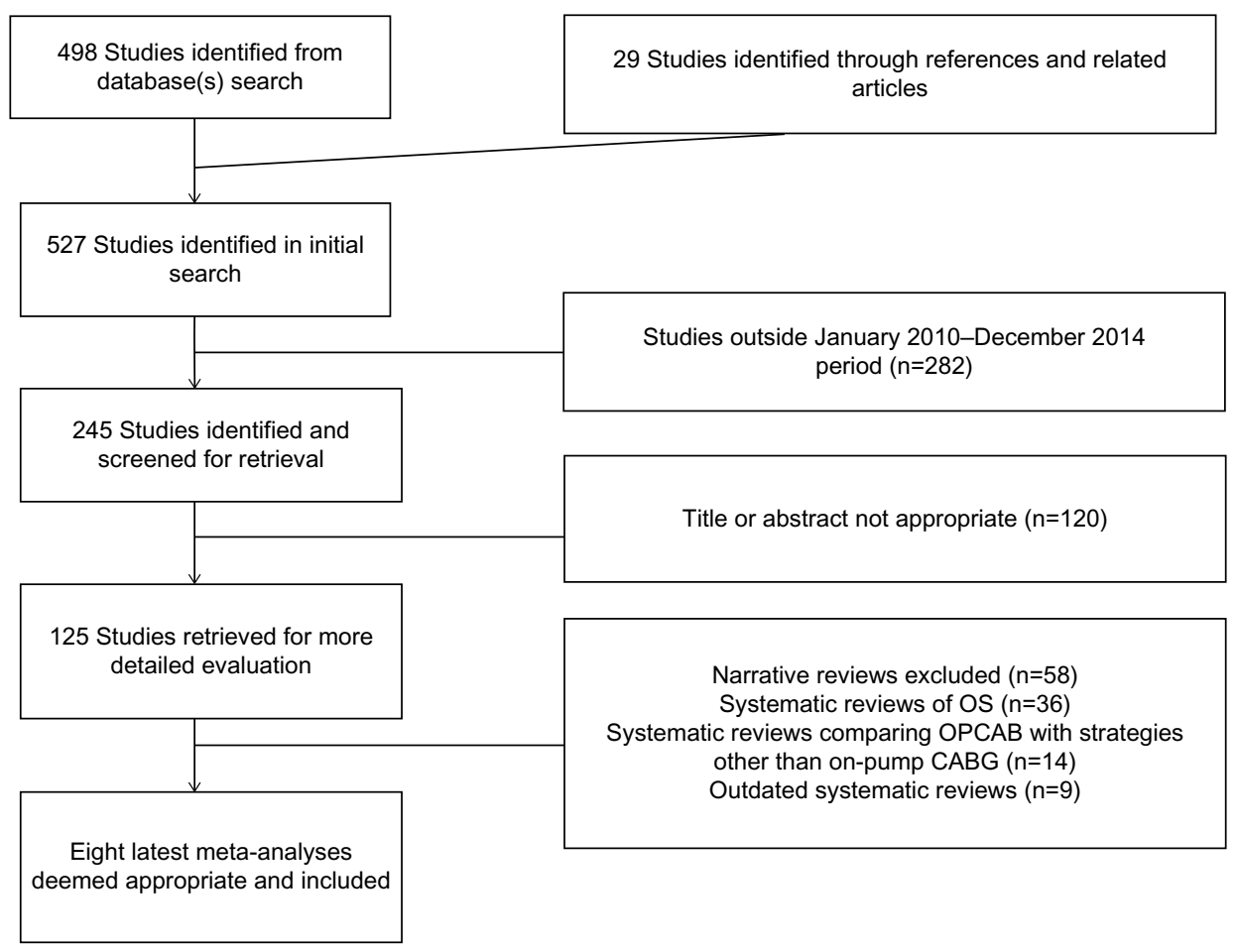

Figure I Search strategy.

Abbreviations: OS, observational studies; OPCAB, off-pump coronary artery bypass; CABG, coronary artery bypass grafting. 
Table I Current best available evidence (meta-analyses of RCTs) comparing off-pump and on-pump coronary artery bypass grafting

\begin{tabular}{|c|c|c|c|c|c|c|}
\hline Author (ref) & Year & No of RCTs & Total patients & No OPCAB & No CPB & Key outcome \\
\hline Sá et al ${ }^{18}$ & 2012 & 47 & 13,524 & 6,758 & 6,766 & $\begin{array}{l}\text { Similar } 30 \text {-day mortality; similar MI; } 20.7 \% \\
\text { reduction in stroke after OPCAB }\end{array}$ \\
\hline Chaudhry et al ${ }^{19}$ & 2014 & 5 & $\mathrm{I}, 486$ & 744 & 742 & Similar mid-term survival \\
\hline Takagi et $\mathrm{al}^{21}$ & 2014 & 8 & 10,954 & 5,481 & 5,473 & Similar mid-term MACCE \\
\hline Zhang et $\mathrm{al}^{22}$ & 2014 & 12 & $8,03 I^{*}$ & $3,894 *$ & $4,137^{*}$ & $\begin{array}{l}\text { Reduced SVG patency after OPCAB; } \\
\text { similar LIMA and RA patency }\end{array}$ \\
\hline Takagi et $\mathrm{al}^{23}$ & 2013 & 12 & II,594 & 5,811 & 5,783 & $\begin{array}{l}38 \% \text { increase in RR rates after } \\
\text { off-pump CABG }\end{array}$ \\
\hline Takagi et $\mathrm{al}^{24}$ & 2014 & 5 & $\mathrm{I}, 486$ & 744 & 742 & $\begin{array}{l}\text { Statistically nonsignificant } 14 \% \text { increase in } \\
\text { long-term mortality after off-pump CABG }\end{array}$ \\
\hline
\end{tabular}

Note: *No of grafts analyzed (no of patients II,594).

Abbreviations: CABG, coronary artery bypass grafting; CPB, cardiopulmonary bypass (on-pump); LIMA, left internal mammary artery; MACCE, major adverse cardiovascular and cerebrovascular events; MI, myocardial infarction; OPCAB, off-pump coronary artery bypass; RA, radial artery; RCT, randomized controlled trial; $R R$, repeat revascularization; SVG, saphenous vein graft; No, number.

showed no statistical significant difference between offpump CABG compared to on-pump CABG (random-effect model: risk ratio $[\mathrm{RR}] 0.938,95 \%$ confidence interval [CI] $0.731-1.203, P=0.612$ ).

\section{Mid-term mortality}

Chaudhry et a ${ }^{19}$ in their recently published meta-analysis reported that off-pump CABG confers similar overall midterm survival when compared with on-pump CABG (hazard ratio [HR] 1.06, 95\% CI 0.95-1.19, $P=0.31$ ). Zhang et al ${ }^{20}$ also confirmed that off-pump CABG does not increase 1-year mortality compared to on-pump CABG.

\section{Mid-term major cardio- and cerebrovascular events}

Takagi et al published a meta-analysis of eight large RCTs including 10,954 patients randomized to off-pump or onpump CABG. A pooled analysis demonstrated no statistically significant difference in off- and on-pump CABG in the random-effects model for mid-term major cardio- and cerebrovascular events (HR 1.10, 95\% CI 0.93-1.29, $P$ for effect $=0.27 ; P$ for heterogeneity $=0.03) .{ }^{21}$

\section{Graft patency}

Zhang et $\mathrm{al}^{22}$ reported an increased risk of occlusion of all grafts (RR 1.35, 95\% CI 1.16-1.57) and saphenous vein grafts (SVGs) (RR 1.41, 95\% CI 1.24-1.60) in the off-pump CABG group, whereas there was no significant difference in graft occlusion of left internal mammary artery (RR 1.15, 95\% CI 0.83-1.59) and radial artery (RR 1.37, 95\% CI 0.76-2.47) grafts between off- and on-pump CABG. ${ }^{22}$ This was a metaanalysis of 12 RCTs, for a total of 3,894 and 4,137 grafts performed during off- and on-pump $\mathrm{CABG}$, respectively.

\section{Repeat revascularization}

Takagi et al ${ }^{23}$ published a meta-analysis to determine whether repeat revascularization rates are increased following off-pump CABG. Pooled analysis of 12 RCTs demonstrated a statistically significant $38 \%$ increase in repeat revascularization rates with off-pump relative to on-pump CABG in the fixed-effects model (odds ratio [OR] 1.38, 95\% CI 1.09-1.76, $P=0.008)$ at $\geq 1$ year. In general, exclusion of any single trial from the analysis did not substantively alter the overall result of this analysis. There was no evidence of significant publication bias.

\section{Long-term survival}

The most recently published pooled analysis of five RCTs $(1,486$ patients $)$ demonstrated a statistically nonsignificant $14 \%$ increase in mortality at $\geq 5$ years with off-pump relative to on-pump CABG (HR 1.14, 95\% CI 0.84-1.56, $P=0.39) .{ }^{24}$

\section{Evidence from meta-analysis of propensity score-matched observational studies}

Kuss et $\mathrm{al}^{25}$ published a systematic review and meta-analysis of 35 propensity score analyses accounting for a total of 123,137 patients. The estimated overall OR was $<1$ for all outcomes, favoring off-pump surgery. This benefit was statistically significant for mortality (OR $0.69 ; 95 \%$ CI $0.60-0.75)$, stroke, renal failure, red blood cell transfusion $(P<0.0001)$, wound infection $(P<0.001)$, prolonged ventilation $(P<0.01)$, inotropic support $(P=0.02)$, and intra-aortic balloon pump support $(P=0.05)$. The OR for myocardial infarction, atrial fibrillation, and reoperation for bleeding were not significant. 


\section{Discussion}

Current best available evidence in the form of meta-analyses and systematic reviews of RCTs as well as propensity scorematched studies confirms comparable impact of off- and on-pump CABG on short-, mid-, and long-term mortality as well as major cardio- and cerebrovascular events with fewer distal anastomoses, poor SVG patency, and increased repeat revascularization rates after off-pump CABG. ${ }^{18-25}$

Since its renaissance nearly 2 decades ago, off-pump $\mathrm{CABG}$ has remained a subject of intense scrutiny. It has been compared with the gold standard on-pump CABG in numerous RCTs as well as large retrospective observational studies. ${ }^{26}$ However, inability of small, prospective, RCTs that have lacked sufficient sample size to demonstrate differences in early and long-term outcomes coupled with misperceptions and misconceptions about incomplete revascularization, reduced long-term graft patency, and increased need for repeat revascularization resulting in inferior long-term survival have prompted opponents of off-pump CABG to demand abandonment of this technique. ${ }^{3}$ On the other hand, proponents of off-pump CABG claim that larger observational studies that are better powered to statistically compare outcomes have shown more favorable in-hospital outcomes and equivalent long-term outcomes with off- and on-pump CABG. ${ }^{26}$

In the current era of evidence-based medicine, the logical approach to comparing the effectiveness of two therapeutic strategies, ie, off- and on-pump CABG, is to evaluate the best available evidence. At present, evidence from systematic reviews and meta-analysis is regarded as the gold standard. ${ }^{5}$ This comparative effectiveness review of off- and on-pump $\mathrm{CABG}$ evaluated the current best available evidence and found comparable effectiveness of off- and on-pump CABG for hard outcomes.

Fewer distal anastomoses coupled with poor SVG patency are well-recognized criticisms of off-pump and also reported by the current best available evidence. ${ }^{3,22}$ Incomplete revascularization and poor graft patency translate into increased repeat revascularization and are associated with worse long-term survival. ${ }^{24}$ Grafting of vessels on the lateral and inferior aspects is no longer impossible due to the availability of modern stabilizers, heart positioning devices, and intracoronary shunts. Hence, it is imperative that any future RCTs reporting incomplete revascularization after off- and on-pump CABG must provide an explanation for failure to completely revascularize. ${ }^{26}$ Moreover, the future trials comparing the effectiveness of off- and on-pump CABG must include a myocardium at risk score, which is a potentially valuable tool to aid in determining the true significance of the non-revascularized territory, because there is a recognized hierarchy of effect, depending on which vessels are left ungrafted and how much myocardium is at risk. ${ }^{27}$ Furthermore, it is equally important to understand that completeness of revascularization and number of grafts should not be used synonymously. In many centers, off-pump CABG is offered to patients who only require one or two grafts, whereas, all else equal, the same patient requiring four or five grafts will not be considered for off-pump CABG. A more logical way to address the issue of completeness of revascularization is to use the index of completeness of revascularization (number of grafts performed divided by the number of grafts needed [number of graftable vessels with angiographically significant stenoses]). ${ }^{26}$

Tangentially mentioned is the fact that some patients are selected for off-pump CABG because of their high risk status and these patients are intentionally offered incomplete revascularization as a "lesser of two evils" or "perfection is the enemy of good" strategy.

Similarly, any RCT comparing graft patency after offand on-pump CABG must provide information about the mode of conduit harvesting as well as the experience of conduit harvester and principal operator, important but often unrecognized confounders. Interestingly, all concerns about suboptimal graft patency in recent years have been predominantly attributed to ROOBY trial. ${ }^{13}$ This trial demonstrated that the patency rate of the off-pump arm was lower than that of the on-pump arm on 12-month angiography, and the 1-year composite adverse outcome rate (death from any cause, nonfatal myocardial infarction, and any reintervention procedure) was higher for off-pump than that for on-pump CABG. Such findings can be explained on the basis that the 53 participating surgeons enrolled on average only eight patients per year during the study period and had unacceptably high conversion rates to on-pump surgery $(12 \%)$ and incomplete revascularization (18\%). Moreover, in $60 \%$ of the cases, a resident was the primary surgeon again raising concerns about the relative inexperience translating into poor graft patency. Another unrecognized confounder that contributed to poor graft patency in the ROOBY trial was the concomitant use of endoscopic vein harvesting $(\mathrm{EVH})$ in 1,471 patients (on-pump $=907$ and off-pump $=564$ ).${ }^{13}$ The incidence of a patient having one or more occluded SVGs on follow-up angiography was $41.3 \%$ in the EVH group, compared with $28.0 \%$ in the open vein harvesting group $(P<0.0001)$. Overall, SVG patency in the EVH group was 
$74.5 \%$, which was significantly worse than the $85.2 \%$ rate in the open vein harvesting group $(P<0.0001) .{ }^{28}$ Since ROOBY trial was recruiting at a time when $\mathrm{EVH}$ was not being widely practiced, the poor vein graft patency secondary to EVH can be attributed to learning curve and relative inexperience of the vein harvesters. Poor conduit quality, a consequence of the learning curve for EVH, has been shown to be a predictor of early graft failure, blunted positive remodeling, and greater negative remodeling. ${ }^{29}$

The unique technical challenges of off-pump CABG fuel the perception that adoption of this myocardial revascularization strategy may lead to poorer outcomes during each surgeon's "learning curve". ${ }^{30}$ Interestingly, those who perceive off-pump CABG as an inferior revascularization strategy with a steep learning curve propose it as a preferred option for high-risk patients. ${ }^{3}$ There is no doubt that despite the substantial learning curve associated with off-pump CABG, early outcomes of off-pump CABG in high-risk patients are better than those of conventional on-pump CABG. ${ }^{31}$ However, these superior outcomes in high-risk patients can only be achieved if off-pump is offered to high- and lowrisk patients alike. In the current era, increasing number of patients with high-risk profile is being referred for CABG. In view of changing the patients' profile, it will be prudent to acknowledge that off-pump CABG is a valuable technique in the armamentarium of cardiac surgeons and is here to stay. ${ }^{26}$ This further emphasizes the need for recognition of off-pump CABG as a subspecialty with structured training program to ensure that myocardial revascularization surgeons of the future can negotiate the learning curve for off-pump safely and perform $\mathrm{CABG}$ for high-risk patients as proficiently as for low-risk patients. There is ample evidence to validate that the learning curve in off-pump CABG can be safely negotiated with appropriate patient selection, individualized grafting strategy, peer-to-peer training of the entire team, and graded clinical experience (preoperative planning, adequate exposure, proximal anastomoses to the aorta, and distal anastomoses initially to anterior wall vessels, followed by inferior wall vessels and then lateral wall vessels). ${ }^{32}$ In fact, centers with established off-pump training programs have consistently shown that off-pump CABG can be safely and successfully taught to trainees without jeopardizing outcomes. ${ }^{33,34}$

Currently, off- and on-pump CABG have comparable outcomes. The concerns about the safety and efficacy of off-pump CABG are not substantiated by the current best available evidence. However, the impact of learning curve on outcomes remains a valid issue.

\section{Disclosure}

The author reports no conflicts of interest in this work.

\section{References}

1. Raja SG, Berg GA. Impact of off-pump coronary artery bypass surgery on systemic inflammation: current best available evidence. J Card Surg. 2007;22(5):445-455.

2. Landis C. Why the inflammatory response is important to the cardiac surgical patient. J Extra Corpor Technol. 2007;39(4):281-284.

3. Lazar HL. Should off-pump coronary artery bypass grafting be abandoned? Circulation. 2013;128(4):406-413.

4. Mack MJ, Duhaylongsod FG. Through the open door! Where has the ride taken us? J Thorac Cardiovasc Surg. 2002;124(4):655-659.

5. Evans D. Hierarchy of evidence: a framework for ranking evidence evaluating healthcare interventions. J Clin Nurs. 2003;12(1):77-84.

6. Kent DM, Trikalinos TA. Therapeutic innovations, diminishing returns, and control rate preservation. JAMA. 2009;302(2):2254-2256.

7. Dahabreh IJ, Sheldrick RC, Paulus JK, et al. Do observational studies using propensity score methods agree with randomized trials? A systematic comparison of studies on acute coronary syndromes. Eur Heart J. 2012;33(15):1893-1901.

8. Byar DP. Why databases should not replace randomized clinical trials. Biometrics. 1980;36(2):337-342.

9. Rosenbaum PR, Rubin DB. The central role of the propensity score in observational studies for causal effects. Biometrika. 1983;70(1):41-55.

10. Rubin DB. The design versus the analysis of observational studies for causal effects: parallels with the design of randomized trials. Stat Med. 2007;26(1):20-36.

11. Tomasulo P. The NLM Gateway: something old, something new. Med Ref Serv Q. 2004;23(1):41-49.

12. Greenhalgh T. How to read a paper. The medline database. BMJ. 1997; 315(7101):180-183.

13. Shroyer AL, Grover FL, Hattler B, et al; Veterans Affairs Randomized On/Off Bypass (ROOBY) Study Group. On-pump versus offpump coronary-artery bypass surgery. $N$ Engl J Med. 2009;361(19): $1827-1837$.

14. Lamy A, Devereaux PJ, Prabhakaran D, et al; CORONARY Investigators. Off-pump or on-pump coronary-artery bypass grafting at 30 days. $N$ Engl J Med. 2012;366(16):1489-1497.

15. Houlind K, Kjeldsen BJ, Madsen SN, et al; DOORS Study Group. On-pump versus off-pump coronary artery bypass surgery in elderly patients: results from the Danish on-pump versus off-pump randomization study. Circulation. 2012;125(20):2431-2439.

16. Diegeler A, Börgermann J, Kappert U, et al; GOPCABE Study Group. Off-pump versus on-pump coronary-artery bypass grafting in elderly patients. N Engl J Med. 2013;368(13):1189-1198.

17. Mackway-Jones K, Carley CD, Morton RJ. Best BETs Critical Appraisal Worksheets. 2015. Available from: http://www.bestbets.org/links/BETCA-worksheets.php. Accessed April 7, 2015.

18. Sá MP, Ferraz PE, Escobar RR, et al. Off-pump versus on-pump coronary artery bypass surgery: meta-analysis and meta-regression of 13,524 patients from randomized trials. Rev Bras Cir Cardiovasc. 2012;27(4): 631-641.

19. Chaudhry UA, Harling L, Rao C, et al. Off-pump versus on-pump coronary revascularization: meta-analysis of mid- and long-term outcomes. Ann Thorac Surg. 2014;98(2):563-572.

20. Zhang B, Zhou J, Li H, Zhou M, Chen A, Zhao Q. Off-pump coronary artery bypass grafting does not increase the 1-year mortality compared to on-pump: a meta-analysis of randomized controlled trials. Int J Cardiol. 2013;169(5):e93-e95.

21. Takagi H, Watanabe T, Mizuno Y, Kawai N, Umemoto T; ALICE (AllLiterature Investigation of Cardiovascular Evidence) Group. A metaanalysis of large randomized trials for mid-term major cardio- and cerebrovascular events following off-pump versus on-pump coronary artery bypass grafting. Interact Cardiovasc Thorac Surg. 2014;18(4):522-524. 
22. Zhang B, Zhou J, Li H, Liu Z, Chen A, Zhao Q. Comparison of graft patency between off-pump and on-pump coronary artery bypass grafting: an updated meta-analysis. Ann Thorac Surg. 2014;97(4):1335-1341.

23. Takagi H, Mizuno Y, Niwa M, Goto SN, Umemoto T; ALICE (AllLiterature Investigation of Cardiovascular Evidence) Group. A metaanalysis of randomized trials for repeat revascularization following off-pump versus on-pump coronary artery bypass grafting. Interact Cardiovasc Thorac Surg. 2013;17(5):878-880.

24. Takagi H, Umemoto T; All-Literature Investigation of Cardiovascular Evidence (ALICE) Group. Worse long-term survival after off-pump than on-pump coronary artery bypass grafting. J Thorac Cardiovasc Surg. 2014;148(5):1820-1829.

25. Kuss O, von Salviati B, Börgermann J. Off-pump versus on-pump coronary artery bypass grafting: a systematic review and meta-analysis of propensityscore analyses. J Thorac Cardiovasc Surg. 2010;140(4): $829-835$.

26. Raja SG, Benedetto U. Off-pump coronary artery bypass grafting: misperceptions and misconceptions. World J Methodol. 2014;4(1):6-10

27. Robertson MW, Buth KJ, Stewart KM, et al. Complete revascularization is compromised in off-pump coronary artery bypass grafting. J Thorac Cardiovasc Surg. 2013;145(4):992-998.
28. Zenati MA, Shroyer AL, Collins JF, et al. Impact of endoscopic versus open saphenous vein harvest technique on late coronary artery bypass grafting patient outcomes in the ROOBY (Randomized On/Off Bypass) trial. J Thorac Cardiovasc Surg. 2011;141(2):338-344.

29. Raja SG, Sarang Z. Endoscopic vein harvesting: technique, outcomes, concerns and controversies. J Thorac Dis. 2013;5(Suppl 6): S630-S637.

30. Song HK, Petersen RJ, Sharoni E, Guyton RA, Puskas JD. Safe evolution towards routine off-pump coronary artery bypass: negotiating the learning curve. Eur J Cardiothorac Surg. 2003;24(6):947-952.

31. Stamou SC, Corso PJ. Coronary revascularization without cardiopulmonary bypass in high-risk patients: a route to the future. Ann Thorac Surg. 2001;71(3):1056-1061.

32. Halkos ME, Puskas JD. Teaching off-pump coronary artery bypass surgery. Semin Thorac Cardiovasc Surg. 2009;21(3):224-228.

33. Murzi M, Caputo M, Aresu G, Duggan S, Angelini GD. Training residents in off-pump coronary artery bypass surgery: a 14-year experience. J Thorac Cardiovasc Surg. 2012;143(6):1247-1253.

34. Bakaeen FG, Sethi G, Wagner TH, et al. Coronary artery bypass graft patency: residents versus attending surgeons. Ann Thorac Surg 2012;94(2):482-488.
Comparative Effectiveness Research

\section{Publish your work in this journal}

Comparative Effectiveness Research is an international, peer reviewed open access journal focusing on comparative effectiveness of health care including preventative health care strategies, diagnostic strategies, diagnostic technology, medical devices, drugs, medical technology, health systems and organization. The manuscript management system

\section{Dovepress}

is completely online and includes a very quick and fair peer-review system. Visit http://www.dovepress.com/testimonials.php to read real quotes from published authors. 